\title{
Base adsorption mechanism over zeolite catalysts at different Al content probed by the tapered element oscillating microbalance (TEOM) \\ DOI:
}

10.1039/C8CP05001E

\section{Document Version}

Accepted author manuscript

Link to publication record in Manchester Research Explorer

Citation for published version (APA):

Brauer, P., \& D'Agostino, C. (2018). Base adsorption mechanism over zeolite catalysts at different Al content probed by the tapered element oscillating microbalance (TEOM). Physical Chemistry: Chemical Physics, 20(39), 25357-25364 . https://doi.org/10.1039/C8CP05001E

\section{Published in:}

Physical Chemistry: Chemical Physics

\section{Citing this paper}

Please note that where the full-text provided on Manchester Research Explorer is the Author Accepted Manuscript or Proof version this may differ from the final Published version. If citing, it is advised that you check and use the publisher's definitive version.

\section{General rights}

Copyright and moral rights for the publications made accessible in the Research Explorer are retained by the authors and/or other copyright owners and it is a condition of accessing publications that users recognise and abide by the legal requirements associated with these rights.

\section{Takedown policy}

If you believe that this document breaches copyright please refer to the University of Manchester's Takedown Procedures [http://man.ac.uk/04Y6Bo] or contact uml.scholarlycommunications@manchester.ac.uk providing relevant details, so we can investigate your claim.

\section{OPEN ACCESS}



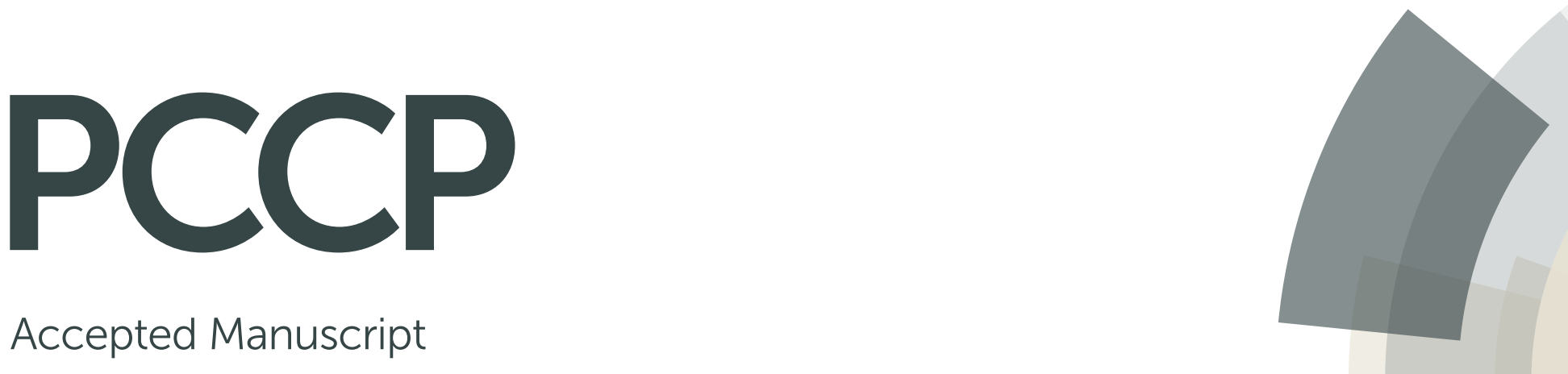

\section{Accepted Manuscript}

This article can be cited before page numbers have been issued, to do this please use: P. Bräuer and C. D'Agostino, Phys. Chem. Chem. Phys., 2018, DOI: 10.1039/C8CP05001E.

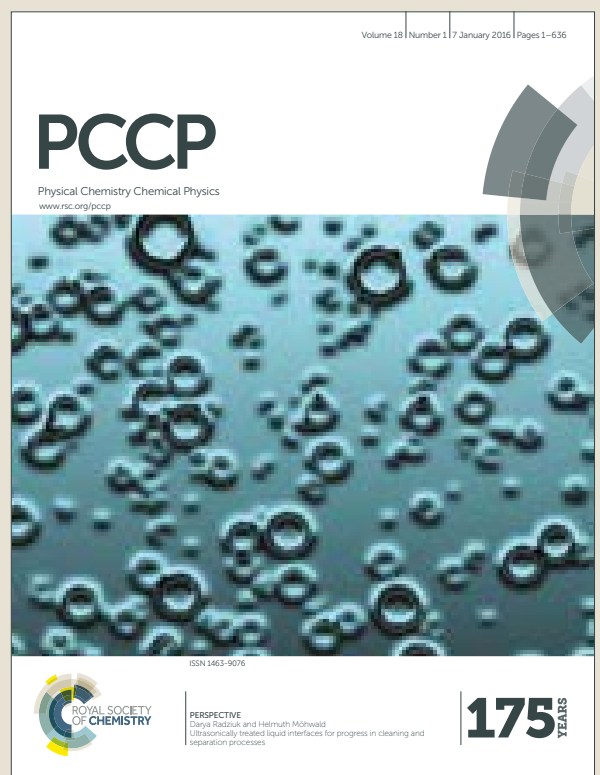

This is an Accepted Manuscript, which has been through the Royal Society of Chemistry peer review process and has been accepted for publication.

Accepted Manuscripts are published online shortly after acceptance, before technical editing, formatting and proof reading. Using this free service, authors can make their results available to the community, in citable form, before we publish the edited article. We will replace this Accepted Manuscript with the edited and formatted Advance Article as soon as it is available.

You can find more information about Accepted Manuscripts in the author guidelines.

Please note that technical editing may introduce minor changes to the text and/or graphics, which may alter content. The journal's standard Terms \& Conditions and the ethical guidelines, outlined in our author and reviewer resource centre, still apply. In no event shall the Royal Society of Chemistry be held responsible for any errors or omissions in this Accepted Manuscript or any consequences arising from the use of any information it contains. 


\title{
Base adsorption mechanism over zeolite catalysts at different Al content probed by the tapered element oscillating microbalance (TEOM)
}

\author{
Pierre Bräuer ${ }^{(a)}$ and Carmine D’Agostino ${ }^{*(b)}$
}

(a) Department of Chemical Engineering and Biotechnology, University of Cambridge, Philippa Fawcett Drive, West Cambridge Site, Cambridge, CB3 0AS, UK

(b) School of Chemical Engineering and Analytical Science, The University of Manchester, The Mill, Sackville Street, Manchester, M13 9PL, UK

*Corresponding Author:

Dr Carmine D’Agostino

School of Chemical Engineering and Analytical Science

The University of Manchester

The Mill, Sackville Street

Manchester

M13 9PL, UK

Email: carmine.dagostino@manchester.ac.uk

Tel: +44(0) 1613064396 


\begin{abstract}
Acidity of zeolites is a paramount property that determines their behaviour in catalytic and adsorption applications. Various techniques have been established over the years to characterise this property qualitatively and quantitatively, using different indicators able to reveal different insights. In this work, for the first time we have used the tapered element oscillating microbalance (TEOM) to study quantitative aspects of internal and external zeolite acidity by measuring sorption dynamics of pyridine and collidine over HZSM5 zeolites with different silica-to-alumina ratio (SAR). The method is able to easily quantify, with a rapid and robust calibration procedure, maximum, physisorbed and chemisorbed uptake of probe molecules. The results show that the uptake of both pyridine and collidine measured by the TEOM increases with decreasing SAR, that is, increase in Al content, consistently with the increase in acid site density at increasing Al content. Most importantly, by providing a robust and easy-to-interpret set of data, the experimental protocol reveals new fundamental insights into the adsorption mechanism as a function of the Al content, showing that at high $\mathrm{Al}$ content chemisorption is the major adsorption mechanism, whereas at low Al content physisorption becomes the dominant mechanism.
\end{abstract}

Key words: tapered element oscillating microbalance, zeolites, acidity, adsorption 


\section{Introduction}

Zeolites are an important class of materials widely used in many applications, including as catalysts, molecular sieves and adsorption media. ${ }^{1,2}$ One important feature of zeolites is that of surface acidity, which affects catalytic activity as well as adsorption kinetics of these materials. ${ }^{3,4}$ Acidic properties of zeolites may be quantified by measuring the uptake of suitable probe molecules, usually base molecules such as ammonia or pyridine, using a variety of techniques. ${ }^{5}$ Established methods include infrared (IR) spectroscopy $^{6,7}$ and temperature-programmed desorption (TPD). ${ }^{8}$ IR is very useful to qualitatively study surface acidity, being able to distinguish between different types of acid sites, most notably Lewis and Brønsted sites; molar extinction coefficients must be determined for each type of acid sites if IR spectra are to be quantified. A recent work on pyridine adsorption over HZSM5 zeolites has demonstrated that by combining IR measurements with elemental analysis and some suitable sample treatment it is possible to a certain extent obtain quantitative information on surface acidity. ${ }^{9}$

For a more quantitative analysis, TPD is perhaps the most widely used technique, which consists in recording a desorption profile of a probe species, such as ammonia or pyridine, as a function of temperature. The TPD profile may be recorded either by a mass spectrometer (MS) or gas chromatography (GC). However, in order to have a proper quantification in terms of uptake of probe species per unit mass of catalyst, a suitable calibration of the TPD profile is required, which may result in lengthy and non-trivial experimental procedures. ${ }^{10}$

An alternative valid approach for tackling such an issue is represented by the use of the tapered element oscillating microbalance (TEOM). ${ }^{11}$ Due to its high mass and temporal resolution, this technique is a powerful tool to study adsorption and desorption processes at equilibrium but also in terms of dynamic processes, before equilibrium is reached. The main principles of the TEOM is that of probing uptake of adsorbing species by measuring changes in oscillation frequency of the tapered element, essentially am oscillating adsorption chamber. The main advantage of using the TEOM for quantifying adsorption uptake is that only the spring constant $K_{0}$ must be calibrated, which can be done in a very rapid and straightforward manner.

Initially, the TEOM was developed to measure the concentration of dust particles in gases ${ }^{12}$ and is still widely used for this purpose. ${ }^{13}$ However, its characteristics such as high mass and temporal resolution make it especially suitable for investigating phenomena in catalysis. Hence, it has been used to elucidate mass changes during reduction treatments ${ }^{14}$ as well as in studies of coke formation on catalysts. ${ }^{15-17}$ The TEOM has also been used to measure 
equilibrium adsorption isotherms ${ }^{18,19}$ and adsorption/desorption kinetics. ${ }^{20-23}$ There has also been research effort to employ the TEOM to obtain an insight into the combined effects of adsorption, diffusion, reaction and coking. ${ }^{24}$

Zhu et al. ${ }^{19}$ used the TEOM to investigate the shape selectivity of propane and propene adsorption on zeolite DD3R and reported a much lower uptake for the alkene compared to the alkane. This was attributed to the different critical-molecular diameter. Rebo et al. ${ }^{23}$ investigated the adsorption of toluene, $p$-xylene and $o$-xylene in HZSM5 at various temperatures $(303-473 \mathrm{~K})$ and partial pressures $(0.2-10 \mathrm{kPa})$ using the TEOM. For each experimental condition the mass uptake order was $p$-xylene $>$ toluene $>o$-xylene. The kinetic diameter of $o$-xylene $(6.8 \AA)$ is larger than the one for $p$-xylene and toluene, which both exhibit a kinetic diameter of $5.9 \AA$. (24) Thus, $o$-xylene is expected to have the lowest uptake. After converting the uptake from mass $\left(\mathrm{g}_{\text {ads }} \mathrm{g}_{\text {zeolite }}{ }^{-1}\right)$ to moles ( $\left.\mathrm{mol}_{\text {ads }} \mathrm{g}_{\text {zeolite }}{ }^{-1}\right)$, the values for $p$-xylene and toluene were very comparable indicating the importance to distinguish between mass and mole uptake of probe molecules.

It is clear that the use of the TEOM to study adsorption and desorption processes over solids has mainly focused on hydrocarbons adsorbed in various catalysts and porous materials. However, to the best of our knowledge, the method has not been used yet to elucidate and quantify acidic properties of zeolites, both in terms of sorption dynamics or uptake of base probe molecules.

In this work we investigate the use of TEOM as an additional tool to characterise internal and external acidic properties of zeolites using pyridine and collidine as probe species. The use of pyridine to probe internal acidity was preferred to that of ammonia, the latter being a much more hazardous substance, more difficult to handle and which may also create issues related to corrosion of piping of the experimental set-up. In addition, the molecular structures of pyridine and collidine are very similar, with the main difference being the size, which is what we are interested in when probing access to the pore space of the zeolites. Hence, the uptake of pyridine and collidine over HZSM5 zeolite samples with different silica-to-alumina (SAR) ratio was chosen as a model system to study both internal and external acidity of the zeolite samples, respectively, probing maximum, physisorbed and chemisorbed uptake, hence validating the use of this experimental approach as a tool to investigate zeolite acidity and give new insights into the adsorption mechanisms over these materials. 


\section{Experimental}

\section{Materials and chemicals}

Pyridine (99\%) was obtained from Alfa Aesar. Collidine (99\%) was obtained from Sigma Aldrich. All chemicals were used as supplied. Several ZSM5 samples with various SAR $\left(\mathrm{SiO}_{2} / \mathrm{Al}_{2} \mathrm{O}_{3}\right)$ values of $23,30,50,80$ and 300 were purchased from Alfa Aesar in the $\mathrm{NH}_{4}^{+}$ form. Zeolite samples were calcined in a furnace with synthetic air $\left(100 \mathrm{~cm}^{3} \mathrm{~min}^{-1}\right.$, Air Liquide) at $773 \mathrm{~K}$ for $4 \mathrm{~h}$ to convert from the $\mathrm{NH}_{4}{ }^{+}$to the $\mathrm{H}^{+}$form, termed HZSM5. Heating and cooling were carried out at $5 \mathrm{~K} \mathrm{~min}^{-1}$. Samples were named according to their SAR, as supplied by Alfa Aesar, and denoted as HZSM5 (SAR). The surface area of these samples is in the range $400-425 \mathrm{~m}^{2} \mathrm{~g}^{-1}$, as stated by Alfa Aesar. Additionally, Sand $\left(\mathrm{SiO}_{2}, 50-70 \mathrm{mesh}\right.$ particle size) was obtained from Sigma-Aldrich.

\section{TEOM set-up and experiments}

The TEOM set-up used in this work to carry out pyridine and collidine sorption experiments is schematically shown in Figure 1. Experiments were performed using a TEOM Rupprecht and Patashnick, 1500 Pulse Mass Analyser (PMA) Model. The TEOM was situated on antivibration pads and equipped with a pressure gauge at the inlet and a thermocouple (K-type, $\pm 0.75 \%$ ) monitoring the sample temperature at the furnace wall. Helium was supplied from a gas cylinder and directed through a molecular sieve moisture trap (Alltech Hydro-Purge II) to mass flow controllers (Tylan General FC-260 and Unit Instruments UFC-1100N, accuracy $\pm 1 \%$ ). Pressure gauges were placed at each mass flow controller outlet together with both non-return valves and pressure release valves, rated to 5 bar, to prevent back flow and as a safety measure. A stainless-steel saturator containing liquid pyridine or collidine was held at $288 \mathrm{~K}$ in a thermostatic bath (Julabo F32-HC).

The helium purge flow around the tapered element was used to prevent the effluent stream from re-entering the packed sample bed. The automated four-port valve allowed for feed switching between dry helium (termed pre-treat stream) and saturator flow (termed carrier stream), that is, helium containing pyridine or collidine vapour. Before adsorption experiments were started, the needle valves on each vent line were adjusted such that the pressure in each line was identical to prevent a change in gas pressure and density within the tapered element when the feed was switched. Data acquisition and control of the flows, temperatures and valves was performed using LabVIEW software v8.6.

For pyridine and collidine sorption experiments HZSM5 powder $(20 \pm 0.5 \mathrm{mg})$ was placed between quartz wool and held in place by a stainless-steel cap containing holes covering the 
end of the element. HZSM5 samples were activated in flowing helium (40 $\left.\mathrm{ml} \mathrm{min}^{-1} \mathrm{STP}\right)$ by heating to $673 \mathrm{~K}$ at $3 \mathrm{~K} \mathrm{~min}^{-1}$, holding for $1 \mathrm{~h}$ and then cooling to $423 \mathrm{~K}$ at $3 \mathrm{~K} \mathrm{~min}^{-1}$. The tapered element was left in flowing helium for at least $1 \mathrm{~h}$ after activation to establish a flat baseline. The feed was then changed to the saturator (carrier stream) containing pyridine or collidine and the mass change was recorded with a gate time of $0.8 \mathrm{~s}$, that is, a frequency measurement was taken every $0.8 \mathrm{~s}$. After maximum adsorption was reached, indicated by reaching a constant frequency, the feed was switched back to helium (pre-treat stream) and the packed sample with adsorbed probe molecules was left for $2 \mathrm{~h}$ to obtain the amount of chemisorbed probe molecules, pyridine or collidine. A helium purge flow (10 $\left.\mathrm{ml} \mathrm{min}^{-1} \mathrm{STP}\right)$ was used for the entire duration of each experiment.

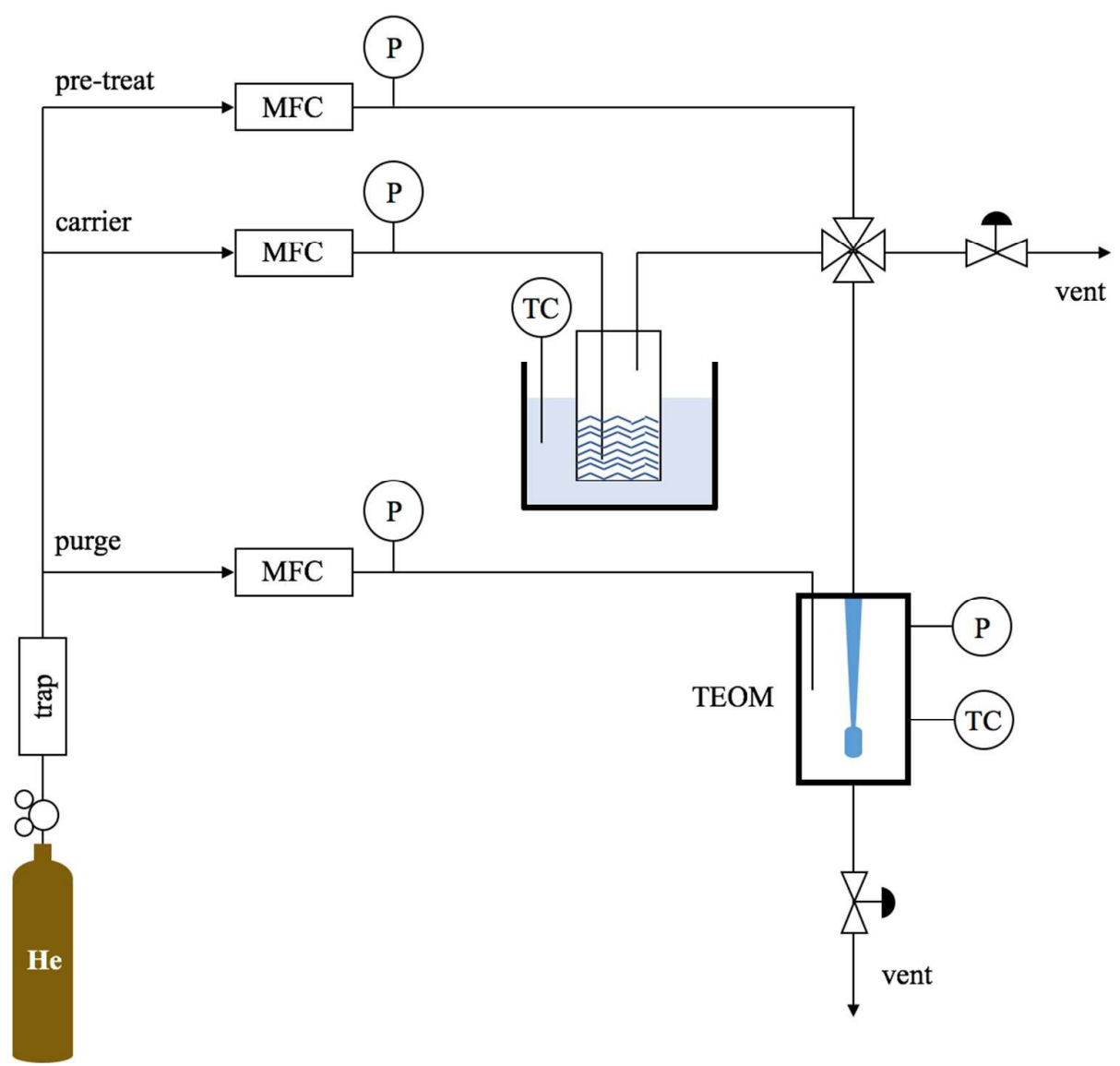

Figure 1. Schematic of TEOM set-up for pyridine and collidine sorption measurements with liquid saturator. $\mathrm{MFC}=$ mass flow controller, $\mathrm{TC}=$ thermocouple, $\mathrm{P}=$ pressure gauge. 


\section{Methodology}

By measuring the variation in the resonance frequency of the tapered element the TEOM probes changes in sample mass. The spring constant $K_{0}$ of the tapered element, which is needed for quantification, is easily calibrated according to:

$$
\Delta M_{\text {cap }}=K_{0}\left(\frac{1}{f_{\text {cap }}^{2}}-\frac{1}{f_{0}^{2}}\right)
$$

In order to do this, TEOM experiments were carried out to measure the oscillation frequency of the tapered element with the cap $\left(f_{\text {cap }}\right)$ and without the cap $\left(f_{0}\right)$; thus, knowing the mass of the cap, $\Delta M_{\text {cap }}$, which was measured as $0.223 \mathrm{~g}$, it is possible to calculate the calibration constant $K_{0}$. The frequency measurements were conducted between temperatures of 323 and $573 \mathrm{~K}$ to investigate if any temperature dependence of the spring constant was present. The observed temperature variation for $K_{0}$ was very small, reflected in the standard deviation of the calculated mean value for the spring constant in the studied temperature range, $2.314 \pm$ $0.001 \mathrm{~N} \mathrm{~m}^{-1}$.

Once a catalyst sample is packed in the tapered element, void space will be present between the catalyst particles. During a TEOM experiment probe molecules are adsorbing and desorbing from the catalyst surface in this void space. Therefore, the density of the so-called "dead volume" might change due to different amounts of probe molecules being present in the gas phase. Depending on the amplitude of this change in gas density the overall observed mass change $\Delta M$ might be affected. In particular:

$$
\Delta M=\Delta M_{a}+\Delta M_{g}=K_{0}\left(\frac{1}{f_{1}^{2}}-\frac{1}{f_{0}^{2}}\right)
$$

where $\Delta M_{a}$ is the mass change due to adsorption on the catalyst surface and $\Delta M_{g}$ is the mass change due to changes in gas density. Therefore, to obtain the mass change due to the adsorption on the catalyst surface $\left(\Delta M_{a}\right)$ only it is normally necessary to subtract results measured on a material with negligible adsorption, such as quartz, from the results measured with the catalyst of interest both acquired at identical experimental conditions.

In this regard, to assess the effect of density change of the dead volume in the tapered element pyridine sorption experiments were carried out at $423 \mathrm{~K}$ with quartz particles (Sand) to minimise adsorption on the surface of the packed material. For this experiment, the change 
in frequency was recorded after switching from the pre-treat stream (helium) to the carrier stream (pyridine vapour), that is, helium gas that passed through the saturator containing liquid pyridine at $288 \mathrm{~K}$. The change in mass recorded after switching to the carrier stream was within the bandwidth of the experimental noise $(\Delta M=1 \mu \mathrm{g})$, which can be regarded as the lower limit for mass changes that can be reliably probed by the used TEOM set-up. Therefore, the effect of the density change of the dead volume due to pyridine was negligible. Collidine has a lower vapour pressure than pyridine at $298 \mathrm{~K}$ the values being $1.99 \mathrm{mmHg}^{25}$ and $20.8 \mathrm{mmHg},{ }^{26}$ respectively. Furthermore, collidine has a lower density than pyridine at $293 \mathrm{~K}$ with 0.913 compared to $0.983 \mathrm{~g} \mathrm{~cm}^{3}$, respectively. ${ }^{27,28}$ Therefore, the mass change of the dead volume caused by collidine is expected to be even smaller than the one measured for pyridine. In summary, for pyridine and collidine TEOM experiments the mass adsorbed on the HZSM5 samples was significantly greater than the mass change in the dead volume, that is, the space between the catalyst particles. The correction of the acquired catalyst data by the quartz data to obtain the mass change that is only due to adsorption on the catalyst surface was therefore not required in this work.

The frequency of data point acquisition of the TEOM, termed gate time, can be set to values between 0.1 and 0.8 seconds. Shorter gate times will result in a higher resolution of the sorption data but will also give a higher normalised standard deviation (NSD), or noise level. The adsorption and desorption dynamics investigated in this work were rather slow and a short gate time was therefore not necessary. Thus, to acquire sorption data with a low NSD, that is low noise level, a gate time of $0.8 \mathrm{~s}$ was selected for all TEOM experiments conducted in this work unless stated otherwise.

\section{Results and discussion}

\section{Pyridine TEOM uptake studies}

The TEOM set-up was used in this work to firstly measure the maximum pyridine uptake at $423 \mathrm{~K}$, which includes both physisorbed and chemisorbed species, while the carrier stream, with a pyridine vapour pressure of 0.016 bar, was flowing through the packed bed of the tapered element containing the zeolite sample. Figure 2 depicts the pyridine sorption profiles measured by the instrument at this temperature. It can be seen from the figure as initially the pyridine uptake onto the zeolite samples steeply rises to a maximum value and remains constant after saturation has been reached. After a time of $0.5 \mathrm{~h}$ the flow is switched from the carrier stream containing pyridine to a stream of dry helium, which desorbs weakly adsorbed pyridine molecules. After a rapid decrease, the profile becomes flat and the pyridine uptake 
reaches a new steady value after a time of approximately $2 \mathrm{~h}$, which corresponds to the amount of chemisorbed pyridine, that is, the amount of pyridine left after the dry helium purge of the zeolite sample saturated with pyridine. Hence, in a single experiment it is possible to quantify and easily visualise maximum, chemisorbed and physisorbed uptake in a rather straightforward fashion and without the need of assumptions that may affect quantification.

In terms of effect of SAR of the zeolite onto the pyridine uptake, the amount of both maximum and chemisorbed pyridine increases with decreasing SAR, that is, increasing total Al content, with the HZSM5 (23) and HZSM5 (300) samples showing the highest and lowest uptake, respectively. This is consistent with previous findings reporting that an increase in $\mathrm{Al}$ content leads to an increase in overall acidity of the zeolite. ${ }^{9}$ The pyridine uptake is comparable for HZSM5 with SAR values of 50 and 80. It is noted that the maximum pyridine uptake of HZSM5 (80) is slightly higher than the maximum pyridine uptake of HZSM5 (50) although the difference is not large.

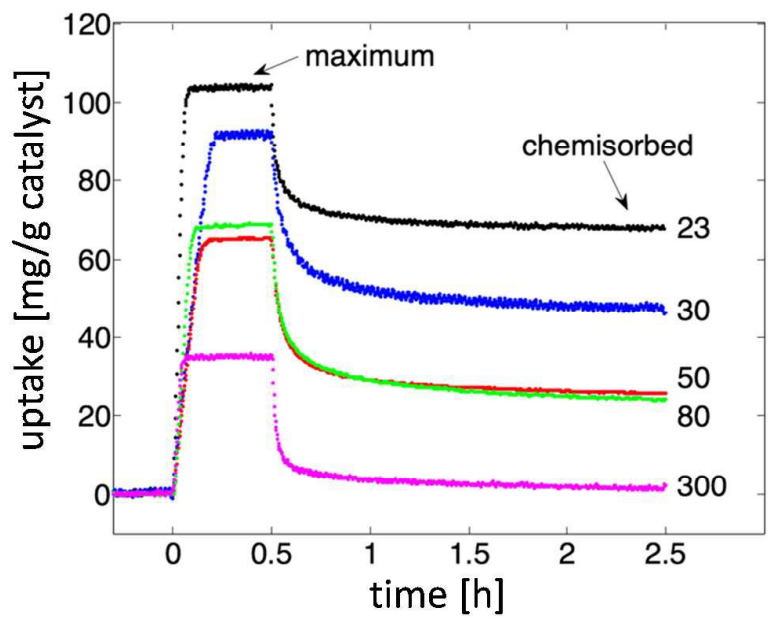

Figure 2. Pyridine sorption profiles measured by the TEOM at $423 \mathrm{~K}$ for HZSM5 with varying SAR (indicated in the plot). The uptake ( $y$-scale) is given in gram of pyridine per gram of catalyst (HZSM5 powder). The time $t$ $=0$ was selected for each plot so that the change in mass starts at the same point on each graph.

The maximum and chemisorbed pyridine uptake were converted to moles using the molecular weight of pyridine, $79.1 \mathrm{~mol} \mathrm{~g}^{-1}$, and are plotted against the total $\mathrm{Al}$ content of the investigated HZSM5 samples in Figure 3 (left). Both types of uptake show almost linear trends with increasing total $\mathrm{Al}$ content. The maximum pyridine uptake of HZSM5 (50) and HZSM5 (80) are similar and within the experimental uncertainty. To further investigate the 
relationship between the maximum number $\left(n_{\max }\right)$ and chemisorbed number $\left(n_{\text {chem }}\right)$ of pyridine molecules the ratio between the two was calculated as follows:

$$
\operatorname{ratio}(\max / \text { chem })=\frac{n_{\max }}{n_{\text {chem }}}
$$

Interestingly, it can be observed in Figure 3 (right) that ratio(max/chem) decreases with increasing total $\mathrm{Al}$ content. However, the ratio(max/chem) values become rather similar for HZSM5 with SAR values between 23 and 80, in particular compared to the significantly higher value for the SAR of 300. This suggests that HZSM5 (300) exhibits the highest and HZSM5 (23) the lowest fraction of weakly adsorbed pyridine molecules that are not able to be retained from the acid sites once the TEOM set-up is switched from the carrier (pyridine vapour) to the pre-treat (helium) stream. Hence, at higher Al content a higher proportion of adsorption sites are chemisorption sites, whereas at low Al content physisorption is the dominant adsorption mechanism.
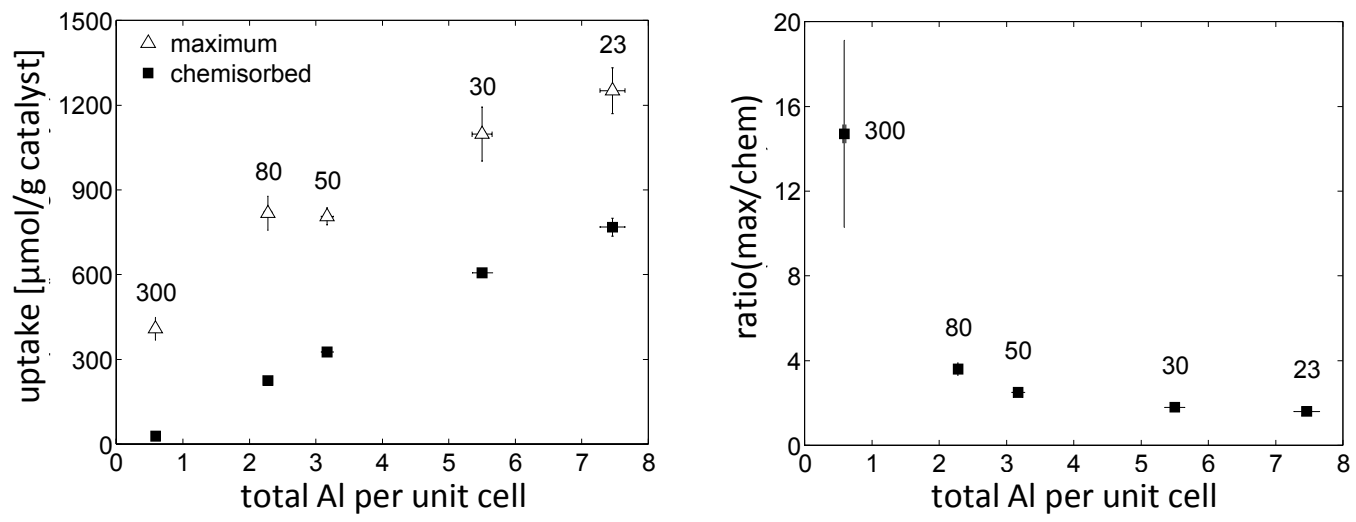

Figure 3. Uptake results (in $\mu \mathrm{mol}$ per gram of catalyst) measured by the TEOM for pyridine adsorbed in HZSM5 with varying SAR (300, 80, 50, 30 and 23 from left to right) at $423 \mathrm{~K}$ : (left) maximum pyridine uptake during carrier stream (pyridine vapour) and amount of chemisorbed pyridine after $2 \mathrm{~h}$ in flowing pre-treat stream (helium). Error bars for the uptake ( $y$-scale) were calculated from the standard deviation of four separate TEOM experiments; (right) values for ratio(max/chem) defined in Equation (3) for pyridine. Error bars ( $y$ scale) were calculated from the standard deviation of the single values.

\section{Collidine TEOM uptake studies}

The probe molecule combination pyridine/collidine has been frequently used to study internal and external acidity in zeolites by means of IR spectroscopy. ${ }^{29,}{ }^{30}$ Whilst pyridine with a kinetic diameter of $5.7 \AA$ is expected to access both the internal and external surface, collidine with a kinetic diameter of $7.4 \AA$ is expected to access the external surface only. 
Using techniques such as IR spectroscopy, the quantification of the fraction of internal and external acid sites, and thus the number of probe molecules adsorbed, requires the knowledge of molar extinction coefficients, which are often not available. Using the TEOM approach, and its easy calibration procedure previously discussed, with the pyridine/collidine combination, the quantification of the total uptake on the internal and external surface of the zeolites, which is important in applications such as adsorptive separation, ${ }^{31}$ becomes rather straightforward.

Figure 4 depicts the collidine sorption profiles measured by the TEOM at $423 \mathrm{~K}$. It can be observed that the maximum and chemisorbed amount of collidine in HZSM5 is significantly less than for pyridine Figure 2. Thus, even though collidine is a stronger base than pyridine, indicated by the proton affinity values of 975 and $930 \mathrm{~kJ} \mathrm{~mol}^{-1}$, respectively, which would give a higher number of adsorbed collidine molecules, the much lower uptake suggests that collidine is not able to enter the HZSM5 pore network. This is expected based on the kinetic diameter of collidine (7.4 $\AA$ ) compared to the size of the HZSM5 pore network (sinusoidal channels: $5.3 \AA \times 5.6 \AA$, straight channels: $5.5 \AA \times 5.1 \AA$ ). ${ }^{32}$ Therefore, collidine will interact only with acid sites located on the external HZSM5 crystal surface or situated at the entrances to the pore network.

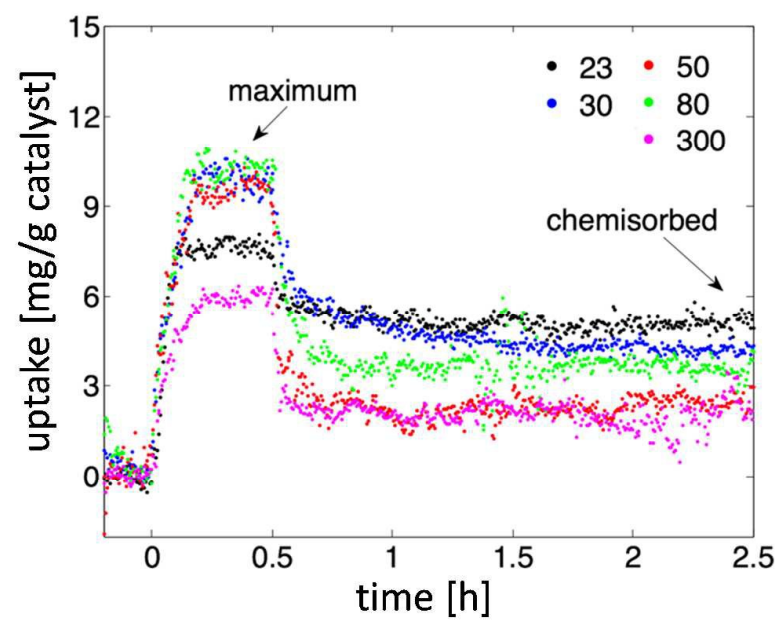

Figure 4. Collidine sorption profiles measured by the TEOM at $423 \mathrm{~K}$ for HZSM5 with varying SAR (indicated in the plot). The uptake ( $y$-scale) is given in gram of collidine per gram of catalyst (HZSM5 powder). The time $t$ $=0$ was selected for each plot so that the change in mass starts at the same point on each graph.

The maximum and chemisorbed collidine uptake on HZSM5 zeolites with varying SAR converted to moles using the molecular weight of collidine, $121.2 \mathrm{~g} \mathrm{~mol}^{-1}$, are shown in 
Figure 5 (left). The ratio of the two, ratio(max/chem) as defined in Equation (3), is depicted in Figure 5 (right). It can be observed in Figure 5 (left) that the number of maximum adsorbed collidine molecules exhibits the highest values for HZSM5 with SAR values of 50 and 80 . This agrees with previous findings reported in the literature that reached the same conclusions using IR techniques. ${ }^{9}$ As collidine adsorbs mostly on the external surface of the zeolite, it is likely that the amount of exposed surface area will affect significantly its uptake. Indeed, it was observed that the collidine uptake can be correlated with the external surface area measured by argon adsorption (see Supporting Information). As for chemisorption, the number of chemisorbed collidine molecules in HZSM5 increases with increasing total Al content, which is qualitatively comparable to the trend observed for the number of chemisorbed pyridine molecules depicted in Figure 3 (left). This can be explained by the increase in amounts of external Brønsted acid sites ${ }^{9}$ that is suggested to significantly contribute to the total number of chemisorbed collidine molecules at higher total Al content.
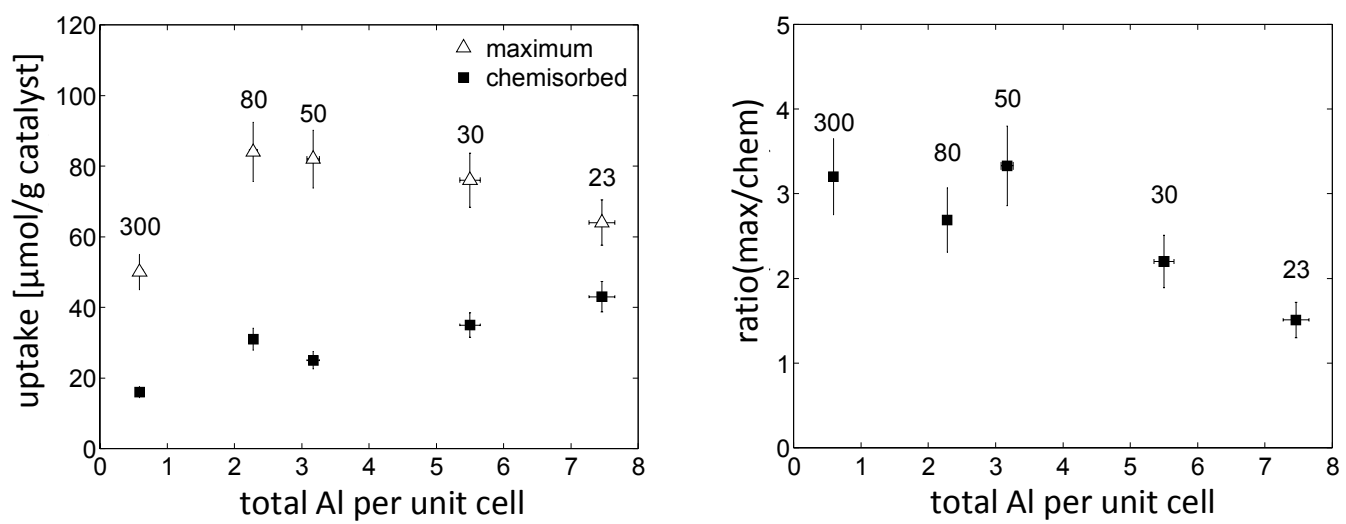

Figure 5. Uptake results (in $\mu \mathrm{mol}$ per gram of catalyst) measured by the TEOM for collidine adsorbed in HZSM5 with varying SAR (300, 80, 50, 30 and 23 from left to right) at $423 \mathrm{~K}$ : (left) maximum collidine uptake during carrier stream (collidine vapour) and amount of chemisorbed collidine after $2 \mathrm{~h}$ in flowing pre-treat stream (helium). Error bars for the uptake ( $y$-scale) were estimated within 10\%; (right) values for ratio(max/ chem) defined in Equation (3) for collidine. Error bars ( $y$-scale) were calculated from the standard deviation of the single values.

From Figure 5 (right) it is possible to observe that ratio(max/chem) for collidine decreases with increasing total $\mathrm{Al}$ content, thus indicating a higher fraction of collidine adsorption sites able to retain the maximum number of adsorbed collidine molecules at higher total Al content. The decrease of ratio(max/chem) was already observed for pyridine, as shown in Figure 3 (right), therefore suggesting that at higher Al content most of the external adsorption sites are chemisorption sites, whereas at low $\mathrm{Al}$ content physisorption is more significant. It is 
likely that the concentration of $\mathrm{Al}$ associated with Brønsted acid sites is primarily affecting the fraction of strong adsorption sites as the number of total and external Brønsted Al was seen to increase with increasing total $\mathrm{Al}$ concentration. ${ }^{9}$ Furthermore, it was previously suggested that the concentration of external Brønsted Al may affect the strength of external terminal silanol sites, ${ }^{7}$ which are therefore likely to contribute to the decreasing trend of ratio(max/chem) with increasing total $\mathrm{Al}$ concentration.

\section{Comparative TEOM analysis of pyridine vs collidine}

It is now of interest to compare in more depth the TEOM results for pyridine and collidine over HZSM5 samples with varying SAR. In order to carry out a direct comparison between the two probe species, the change in mass measured by the TEOM was converted to moles. The sorption profiles in terms of molar uptake for both pyridine and collidine are shown in Figure 6 . The $y$-scale (uptake in $\mu$ mol per gram of catalyst) of both plots differs by an order of magnitude and it can be observed that the total and chemisorbed pyridine uptake is significantly higher than for collidine regardless of SAR. It is noted that the absolute uptake values reported in Figure 6 compare very well with those reported in the literature for similar systems, ${ }^{33,34}$ which further validates the quantitative data reported in this work. For example, Losch et al. ${ }^{34}$ have reported total acid site density values for various HZSM5 samples that range between approximately 300 and $1500 \mu \mathrm{mol} \mathrm{g}{ }^{-1}$, which is exactly the same range observed in this study with pyridine.
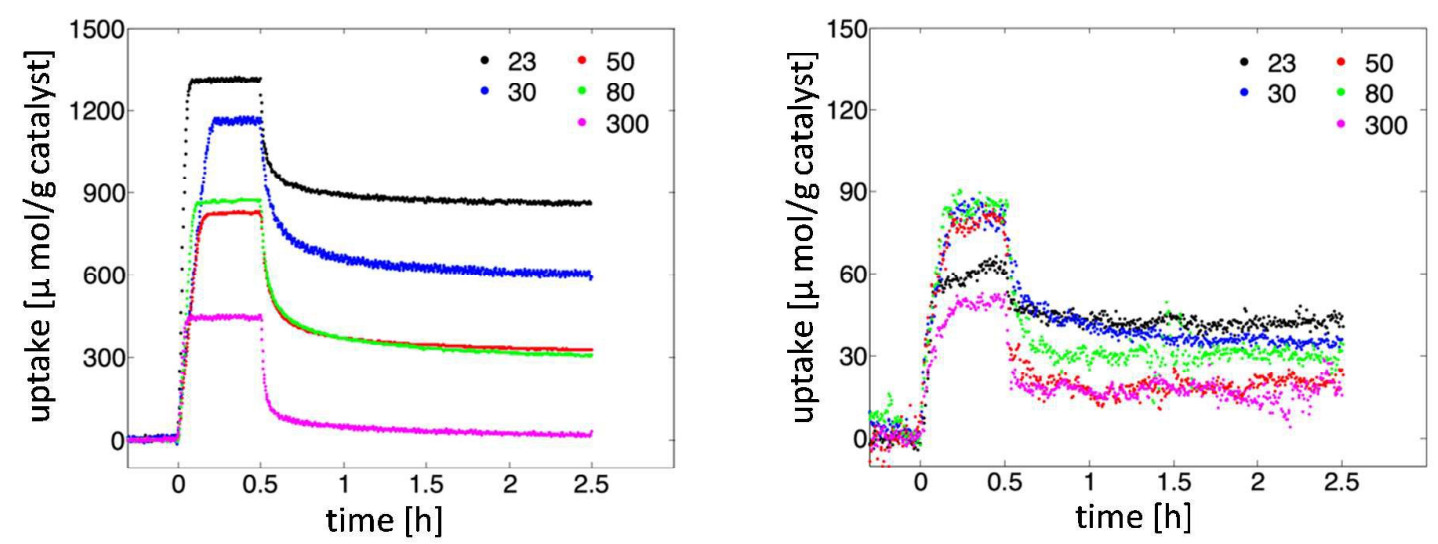

Figure 6. TEOM sorption profiles of (left) pyridine and (right) collidine on HZSM5 zeolites with varying SAR (indicated in the plots) at $423 \mathrm{~K}$. The $y$-scales differ by an order of magnitude. 
From the plots in Figure 6 it is also possible to extract data on the kinetics of uptake by taking the initial slope of the TEOM profile. For the case of pyridine, values of 313, 105, 104, 115 and $115 \mu \mathrm{mol} \mathrm{g}^{-1} \mathrm{~min}^{-1}$ were obtained for SAR values of 23, 30, 50, 80 and 300, respectively. This indicates that the rate of uptake of the most acidic sample, SAR of 23, is much greater compared to the other samples and suggests that to some extent acidity affects not only the final uptake value but also the rate at which probe species are adsorbed. It is noted that some studies seem to indicate that zeolites with lower SAR values have higher heat of adsorption, which could be linked to the higher rate of uptake reported here, although it has to be said that such studies have not been thoroughly conclusive. ${ }^{35-39}$ For the collidine samples accurate values of the initial slope could not be obtained because of the much nosier data due to much lower uptakes.

To compare the maximum amount of pyridine and collidine molecules adsorbed on HZSM5 the following ratio is defined:

$$
\text { ratio }_{\text {max }}=\frac{n_{\text {pyridine, } \text { max }}}{n_{\text {collidine, } \text { max }}}
$$

In Equation (4) $n_{\text {pyridine,max }}$ and $n_{\text {collidine,max }}$ are the maximum number of pyridine and collidine molecules adsorbed, respectively. Similarly, the same ratio can be defined for the chemisorbed species:

$$
\text { ratio }_{\text {chem }}=\frac{n_{\text {pyridine,chem }}}{n_{\text {collidine,chem }}}
$$

where $n_{\text {pyridine,chem }}$ and $n_{\text {collidine,chem }}$ are the chemisorbed number of pyridine and collidine molecules adsorbed, respectively. The change of ratio ${ }_{\text {max }}$ and ratio ${ }_{\text {chem }}$ with the total $\mathrm{Al}$ content in HZSM5 is depicted in Figure 7. It can be seen that both ratios increase with increasing total $\mathrm{Al}$ content indicating that significantly more pyridine molecules are interacting with acid sites than collidine as the SAR decreases, that is, the Al content increases. A steep increase is observed for ratio ${ }_{\text {chem }}$ between SAR values of 300 and 50 followed by a less strong dependence on the total Al content for SAR values between 50 and 23. This indicates a more pronounced increase in external adsorption sites relative to the increase in total adsorption sites for SAR values of 23 and 30, which is likely due to the significantly higher number of external Brønsted acid sites for those samples. 


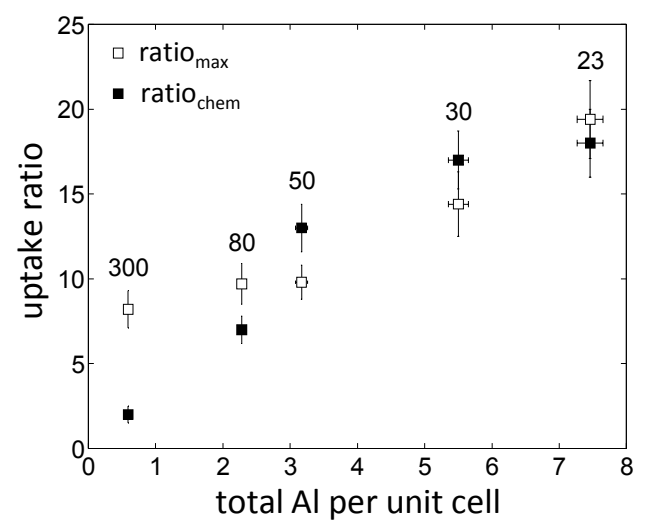

Figure 7. Comparison of pyridine and collidine TEOM results as ratio for number of pyridine molecules relative to number of collidine molecules for maximum amount, ratio ${ }_{\max }$, Equation (4), and chemisorbed amount, ratio $_{\text {chem }}$, Equation (5).

From Figure 7 it can also be observed that for the SAR of 300 the ratio ${ }_{\max }$ is significantly

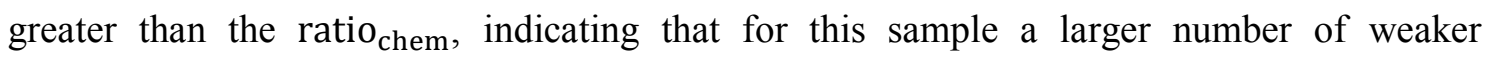
(physisorption) acid sites that are located inside the pore network, relative to the other SAR values.

\section{Conclusions}

In this work we have used the tapered oscillating microbalance (TEOM) technique to study quantitative aspects of zeolite acidity by probing the uptake of pyridine and collidine over a range of HZSM5 zeolites with different silica-to-alumina ratio (SAR) values. It is shown that the technique can easily quantify maximum, physisorbed and chemisorbed uptake of probe molecules (both on the internal and external surface) through a simple and rapid calibration procedure. The results reveal that the uptake measured by the TEOM of both pyridine and collidine increases with decreasing SAR, that is, increase in $\mathrm{Al}$ content, which is consistent with the increase in acid site density at increasing Al content. In addition, we find that at high $\mathrm{Al}$ content most of the adsorption sites are chemisorption sites, whereas for low $\mathrm{Al}$ content physisorption becomes more significant; hence, the technique is able to reveal that at high $\mathrm{Al}$ content chemisorption is the major adsorption mechanism, whereas at low Al content physisorption becomes the dominant mechanism, which gives new fundamental insights into how the $\mathrm{Al}$ content affects the adsorption mechanism in these materials.

\section{Acknowledgements}

We would like to thank Prof. Lynn Gladden for the support and for providing the facilities to carry out this work. We also acknowledge Dr Andy York from Johnson Matthey. 


\section{References}

1. G. Perego, G. Bellussi, C. Corno, M. Taramasso, F. Buonomo and A. Esposito, New Developments in Zeolite Science and Technology, Stud. Surf. Sci. Catal., 1986, 28, $129-136$.

2. G. Öhlmann, H. Pfeifer and R. Fricke, Catalysis and Adsorption by Zeolites, Elsevier, Amsterdam, 1991.

3. N. Rahimi and R. Karimzadeh, Catalytic cracking of hydrocarbons over modified ZSM-5 zeolites to produce light olefins: A review, Applied Catalysis A: General, 2011, 398, 1-17.

4. A. Westermann and B. Azambre, Impact of the zeolite structure and acidity on the adsorption of unburnt hydrocarbons relevant to cold start conditions, J. Phys. Chem. $C, 2016,120,25903-25914$.

5. W. E. Farneth and R. J. Gorte, Methods for characterizing zeolite acidity, Chem. Rev., 1995, 95, 615-635.

6. J. Ryczkowski, IR spectroscopy in catalysis, Catal. Today, 2001, 68, 263-381.

7. P. Brauer, O. Situmorang, P. L. Ng and C. D'Agostino, Effect of Al content on the strength of terminal silanol species in ZSM-5 zeolite catalysts: a quantitative DRIFTS study without the use of molar extinction coefficients, Phys. Chem. Chem. Phys., 2018, 20, 4250-4262.

8. W. Suprun, M. Lutecki, T. Haber and H. Papp, Acidic catalysts for the dehydration of glycerol: Activity and deactivation, J. Mol. Catal. A-Chem., 2009, 309, 71-78.

9. P. Bräuer, P. L. Ng, O. Situmorang, I. Hitchcock and C. D'Agostino, Effect of Al content on number and location of hydroxyl acid species in zeolites: a DRIFTS quantitative protocol without the need for molar extinction coefficients, $R S C$ Advances, 2017, 7, 52604-52613.

10. V. Rakić and L. Damjanović, in Calorimetry and Thermal Methods in Catalysis, ed. A. Auroux, Springer Berlin Heidelberg, Berlin, Heidelberg, 2013, pp. 131-174.

11. E. Ruppecht, M. Meyer and H. Patashnick, The tapered element oscillating microbalance as a tool for measuring ambient particulate concentrations in real time, J. Aerosol Sci, 1992, 23, 635-638.

12. H. Patashnick and E. G. Rupprecht, Continuous PM-10 measurements using the tapered element oscillating microbalance, Journal of the Air \& Waste Management Association, 1991, 41, 1079-1083.

13. D. Green and G. W. Fuller, The implications of tapered element oscillating microbalance (TEOM) software configuration on particulate matter measurements in the UK and Europe, Atmos. Environ., 2006, 40, 5608-5616.

14. J. E. Rekoske and M. A. Barteau, Isothermal reduction kinetics of titanium dioxidebased materials, J. Phys. Chem. B, 1997, 101, 1113-1124.

15. K. Liu, S. C. Fung, T. C. Ho and D. S. Rumschitzki, Kinetics of catalyst coking in heptane reforming over Pt-Re/ $\mathrm{Al}_{2} \mathrm{O}_{3}$, Ind. Eng. Chem. Res., 1997, 36, 3264-3274.

16. D. Chen, H. P. Rebo, K. Moljord and A. Holmen, in Stud. Surf. Sci. Catal., eds. C. H. Bartholomew and G. A. Fuentes, Elsevier, 1997, vol. 111, pp. 159-166.

17. D. Chen, H. P. Rebo, K. Moljord and A. Holmen, Influence of coke deposition on selectivity in zeolite catalysis, Ind. Eng. Chem. Res., 1997, 36, 3473-3479.

18. W. Zhu, J. M. van de Graaf, L. J. P. van den Broeke, F. Kapteijn and J. A. Moulijn, TEOM: A unique technique for measuring adsorption properties. Light alkanes in silicalite-1, Ind. Eng. Chem. Res., 1998, 37, 1934-1942. 
19. W. Zhu, F. Kapteijn, J. A. Moulijn, M. C. den Exter and J. C. Jansen, Shape selectivity in adsorption on the all-silica DD3R, Langmuir, 2000, 16, 3322-3329.

20. F. Hershkowitz and P. D. Madiara, Simultaneous measurement of adsorption, reaction, and coke using a pulsed microbalance reactor, Ind. Eng. Chem. Res., 1993, 32, 2969-2974.

21. W. Zhu, F. Kapteijn and J. A. Moulijn, Diffusion of linear and branched C-6 alkanes in silicalite-1 studied by the tapered element oscillating microbalance, Microporous and Mesoporous Materials, 2001, 47, 157-171.

22. E. Alpay, D. Chadwick, L. S. Kershenbaum, P. J. Barrie, C. Sivadinarayana and L. F. Gladden, TEOM analysis of the equilibria and kinetics of n-hexane and n-heptane adsorption on FCC catalyst/silicalite, Chem. Eng. Sci., 2003, 58, 2777-2784.

23. H. P. Rebo, D. Chen, M. S. A. Brownrigg, K. Moljord and A. Holmen, Adsorption and diffusion in HZSM-5 zeolite studied by an oscillating microbalance, Collect. Czech. Chem. Commun., 1997, 62, 1832-1842.

24. S. van Donk, A. Broersma, O. L. J. Gijzeman, J. A. van Bokhoven, J. H. Bitter and K. P. de Jong, Combined diffusion, adsorption, and reaction studies of n-hexane hydroisomerization over $\mathrm{Pt} / \mathrm{H}-$ mordenite in an oscillating microbalance, Journal of Catalysis, 2001, 204, 272-280.

25. J. Chao, C. T. Lin and T. H. Chung, Vapor-pressure of coal chemicals, J. Phys. Chem. Ref. Data, 1983, 12, 1033-1063.

26. T. E. Daubert, T. E. Daubert and R. P. Danner, Physical and thermodynamic properties of pure chemicals: data compilation, Taylor \& Francis, Washington, DC, 1989.

27. E. R. Adlard, Hawley's condensed chemical dictionary, 16th edition, Chromatographia, 2017, 80, 997-997.

28. J. K. Whitesell, The Merck Index, 12th Edition: An encyclopedia of chemicals, drugs \& biologicals, Journal of the American Chemical Society, 1998, 120, 2209-2209.

29. K. Mlekodaj, K. Tarach, J. Datka, K. Gora-Marek and W. Makowski, Porosity and accessibility of acid sites in desilicated ZSM-5 zeolites studied using adsorption of probe molecules, Microporous and Mesoporous Materials, 2014, 183, 54-61.

30. F. Thibault-Starzyk, I. Stan, S. Abello, A. Bonilla, K. Thomas, C. Fernandez, J. P. Gilson and J. Perez-Ramirez, Quantification of enhanced acid site accessibility in hierarchical zeolites - The accessibility index, Journal of Catalysis, 2009, 264, 11-14.

31. S. Kulprathipanja, Zeolites in industrial separation and catalysis, Wiley-VCH, Weinheim, 2010.

32. H. van Koningsveld, in Stud. Surf. Sci. Catal., eds. R. Xu, Z. Gao, J. Chen and W. Yan, Elsevier, 2007, vol. 170, pp. 698-704.

33. O. A. Abdelrahman, K. P. Vinter, L. Ren, D. Xu, R. J. Gorte, M. Tsapatsis and P. J. Dauenhauer, Simple quantification of zeolite acid site density by reactive gas chromatography, Catalysis Science \& Technology, 2017, 7, 3831-3841.

34. P. Losch, T. C. Hoff, J. F. Kolb, C. Bernardon, J. P. Tessonnier and B. Louis, Mesoporous ZSM-5 zeolites in acid catalysis: top-down vs. bottom-up approach, Catalysts, 2017, 7.

35. D. T. Chen, S. B. Sharma, I. Filimonov and J. A. Dumesic, Microcalorimetric studies of zeolite acidity, Catal. Lett., 1992, 12, 201-211.

36. S. B. Sharma, B. L. Meyers, D. T. Chen, J. Miller and J. A. Dumesic, Characterization of catalyst acidity by microcalorimetry and temperature-programmed desorption, Applied Catalysis A: General, 1993, 102, 253-265.

37. M. R. Gonzalez, S. B. Sharma, D. T. Chen and J. A. Dumesic, Thermogravimetric and microcalorimetric studies of ZSM-5 acidity, Catal. Lett., 1993, 18, 183-192. 
38. D. J. Parrillo and R. J. Gorte, Characterization of acidity in H-ZSM-5, H-ZSM-12, HMordenite, and H-Y using microcalorimetry, The Journal of Physical Chemistry, 1993, 97, 8786-8792.

39. D. J. Parrillo, C. Lee, R. J. Gorte, D. White and W. E. Farneth, Comparison of the acidic properties of $\mathrm{H}-[\mathrm{Al}] \mathrm{ZSM}-5$, $\mathrm{H}-[\mathrm{Fe}] \mathrm{ZSM}-5$, and $\mathrm{H}-[\mathrm{Ga}] \mathrm{ZSM}-5$ using microcalorimetry, hexane cracking, and propene oligomerization, The Journal of Physical Chemistry, 1995, 99, 8745-8749. 